\title{
Study Reference Citation Description
}

National Cancer Institute

\section{Source}

National Cancer Institute. Study Reference Citation Description. NCI Thesaurus. Code C94130.

A bibliographical reference in a format acceptable to the publisher of the reference material. 